\title{
Ortega Muñoz, Víctor J. (2018), ¡Extra, extra! Poder, información y control de la sociedad española en las noticias de sucesos, 1881-1923, Pórtico, Zaragoza, 400 págs. ISBN: 978-84-7956-174-1.
}

Durante las tres últimas décadas la historia comparada ha dado lugar a numerosos estudios en diferentes países. Ese interés es visible en los trabajos de Otto Hintze ${ }^{1}$, Nancy Green ${ }^{2}$ y Richard J. Evans ${ }^{3}$ en Europa, o en las obras pioneras de Sewell ${ }^{4}$ y Fredrikson ${ }^{5}$ en Norteamérica. La necesidad de "hacer una historia comparada que haga justicia a la diversidad y el pluralismo"6, es también una premisa de la historia de las mujeres y la historia de género, como ha apuntado recientemente Anne $\mathrm{Cove}^{7}$, que resalta la afinidad de muchos de sus registros históricos con el método comparativo. Así ha quedado reflejado, por citar solo dos ejemplos, en la voluminosa obra de Michelle Perrot y Georges Duby ${ }^{8}$ : Historia de las mujeres en occidente y en el libro coordinado por Gisela Bock y Pat Thane ${ }^{9}$, en el que se abordan diferentes estudios sobre la maternidad y las políticas de género en los Estados de Bienestar europeos.

1. Hintze, Otto (1964), "Soziologische und geschichtliche Staatsauffassung», en Oestreich, G. (ed.), Soziologie und Geschichte. Gesammelte Abhandlungen, vol. 2, Vandenhoeck und Ruprecht, Göttingen, pp. 239-305.

2. Green, Nancy (1990), "L'histoire comparative et le champs des études migratoires", Annales. Économies, Sociétés, Civilisations, 45, pp. 1335-1345.

3. Evans, Richard J. (1977), The Feminists: Women's Emancipation Movements in Europe, America, and Australasia, 1840-1920, Croom Helm, London.

4. Sewell, William. H. (1967), "Marc Bloch and the logic of comparative history", History and Theory, 6, 2, pp. 208-218.

5. Fredrickson, George M. (1985), "Giving a Comparative Dimension to American History: Problems and Opportunities", The Journal of Interdisciplinary History, 16, 1, p. 109.

6. Ibidem.

7. Cove, Anne (ed.) (2012), Historia comparada de las mujeres. Nuevos enfoques, Trabe, Oviedo, pp. 21-55.

8. Duby, Georges y Perrot, Michelle (dirs.) (1991-93), Historia de las mujeres en Occidente, 5 vols., Taurus Minor/Santillana, Madrid.

9. Bock, Gisela y Thane, Pat (coords.) (1991), Maternidad y politicas de género: La mujer en los estados de bienestar europeos 1880-1950, Routledge, New York. 
Ahora bien, frente al éxito cosechado por las unidades comparadas en diversos países, la historiografía española se ha mostrado, en general, más reticente con la fundamentación teórica y la práctica de este campo de la historia. Uno de los primeros artículos sobre las propuestas metodológicas y las variadas tendencias de la historia comparada fue el del profesor Charles Maier, director del Centros de Estudios Europeos de la Universidad de Harvard (1994-2001), publicado en la revista Studia Histórica. Historia Contemporánea de la Universidad de Salamanca ${ }^{10}$. En sus páginas se refleja la trayectoria y los debates a que ha dado lugar el método comparado en autores como Tocquevile, Marx, Engels y Weber, la polémica académica surgida en torno a la obra de Marc Bloch: La sociedad feudal $^{11}$, autor que aborda los rasgos y matices del feudalismo en la Europa occidental y central durante los siglos VIII-XIII, así como la posterior utilización del método comparado, tanto en su sentido histórico como antropológico, de la que se recogen abundantes muestras en la revista Annales: Economies, Societés, Civilizations.

El libro de Víctor José Ortega Muñoz responde a la necesidad de plantear un estudio comparado sobre las noticias de sucesos en España durante buena parte de la Restauración, concretamente durante el periodo 1881-1923, utilizando dos periódicos: La Vanguardia de Barcelona y La Unión Mercantil de Málaga, ambos representativos de la prensa impulsada por un sector de la burguesía. Una de las primeras certezas que se desprenden de la lectura de la obra es la escasez de investigaciones comparadas sobre la historia de la prensa española, aunque la historiadora de la comunicación Amparo Moreno Sardá ${ }^{12}$ ya había puesto de manifiesto su interés hace cuatro décadas. Una carencia que resalta el interés del texto que reseñamos, realzado por el aliciente que tienen las noticias de sucesos a la hora de reflejar las tensiones sociales y las vivencias conflictivas en la vida cotidiana y reflexionar sobre el papel socializador de la prensa a la hora de primar la necesidad de mantener el orden frente al caos.

En este sentido hay que recordar que el concepto de noticias de sucesos está intrínsecamente vinculado a la prensa moderna y a la incipiente sociedad de masas que fue surgiendo conforme se acercaba el cruce de los siglos XIX-XX. La configuración del periódico con un sentido empresarial originó nuevas necesidades a un medio en vías de expansión y que encontró en dichas noticias un reclamo comercial destinado a incrementar el interés del público, engrosar la tirada y la venta de periódicos, así como un instrumento de control social para señalar los

10. MaIer, Charles (1992-1993), "La historia comparada", Studia Historica, Historia Contemporánea, X-XI, pp. 11-32.

11. Bloch, Marc (1988), La sociedad feudal, Akal, Madrid.

12. Moreno SARDÁ, Amparo (1975), Història de la premsa de successos a Espanya. Aproximació a una metodologia científica per l'estudi de la Història de la Premsa. Tesis de licenciatura de la Facultad de Historia, Universitat de Barcelona. 
peligros que acarreaba la ruptura de la normalidad y crear un clima de alarma social en la opinión pública. Sin embargo, la historia de la prensa ha concedido escasa importancia a este tipo de noticias que reflejan los vericuetos de una época a través de crímenes, atracos, robos, violaciones, asaltos, accidentes y otros hechos perpetrados con violencia o generados por catástrofes naturales.

En este sentido, el libro de Víctor José Ortega Muñoz refleja que el tratamiento, la extensión y la entidad de las páginas de sucesos se fueron consolidando a medida que se desarrollaban las empresas periodísticas durante el sistema canovista. El autor sitúa la investigación en tres grandes ámbitos: la historia social de la prensa, la historia de la vida cotidiana y la historia del poder, utilizando el método comparativo, la perspectiva de género y el concepto de androcentrismo. Estos ámbitos contribuyen a destacar que las noticias de sucesos implican múltiples registros entre los que sobresalen acontecimientos teñidos de violencia (raptos, abusos sexuales, violaciones, asesinatos) cuya visibilidad es mayor entre las clases populares. Es harto interesante comprobar, por otra parte, que las noticias ubicadas en la esfera privada reflejan la situación de pobreza, discriminación y dependencia de las mujeres de los sectores subalternos y marginales, brindándonos una rica información sobre ellas imposible de encontrar en otras fuentes. Sin embargo, la prensa apenas refleja el protagonismo femenino en los espacios públicos, salvo cuando se ocupa de los casos de violencia de género, que son descritos con tonos paternalistas o irónicos realzando el desprestigio social de victimarios y víctimas. Las mujeres son, pues, sujetos no noticiables, de ahí que se hayan silenciado durante mucho tiempo sus luchas sociales, las huelgas promovidas por tejedoras y cigarreras o las protestas de las campesinas. Privadas de ciudadanía e "invisibilizadas", sus experiencias eran silenciadas o denostadas, mientras se multiplicaban las voces femeninas contra la sociedad patriarcal y surgían perfiles como los de Emilia Pardo Bazán, Belén Sárraga, Carmen de Burgos, Teresa Claramunt, Soledad Gustavo o Margarita Nelken, mujeres vinculadas a diferentes culturas políticas, que clamaban por los derechos civiles, sociales y políticos ${ }^{13}$.

Los medios de comunicación de masas fueron estudiados de forma temprana a finales de los años veinte del pasado siglo. El concepto acuñado por pioneros como Lasswell, cuyo análisis fue revisado posteriormente por Lazarsfield o Merton $^{14}$, reflejaba, desde la Gran Guerra, la relación entre propaganda y democracia evidenciada en la alienación y unificación social de los sistemas industriales y capitalistas. Este paradigma nos permite reflexionar sobre la función ideológica que ejercieron las clases privilegiadas a través de sus tribunas de prensa, en sintonía con sus propios intereses y con los del Estado español, así como detectar un

13. Martínez, Cándida; Pastor, Reyna; de la Pascua, María José y Tavera, Susana (dirs.) (2000), Mujeres en la Historia de España. Enciclopedia Biográfica, Planeta, Barcelona.

14. Mattelart, Armand y Mattelart, Michèle (1997), Historia de las teorías de la Comunicación, Paidós, Barcelona, pp. 28-39. 
concepto de poder ligado estrechamente a la información, como se pone de relieve en la presente monografía. La influencia ejercida por la prensa en el público lector y el creciente valor de lo impreso anunciaban los comienzos de una sociedad de masas que no puede entenderse sin esa relación.

La obra de Víctor José Ortega Muñoz se compone de seis capítulos. El primero de ellos introduce el objeto de estudio y plantea la metodología utilizada. En el segundo el autor contextualiza el marco histórico para más tarde, en el tercero, explicar el esquema teórico que vertebra la investigación. En el cuarto plantea el análisis de las noticias de sucesos recogidas en el diario La Vanguardia, seleccionadas y ordenadas según una adscripción tipológica que recoge los actos contra la integridad física de las personas, los actos contra la propiedad privada, los accidentes, las lesiones, los actos contra la costumbre y la moral y, por último, las noticias judiciales. Las informaciones sobre muertes violentas eran un foco de atracción para promover la venta de periódicos e incrementar su lectura. Los actos contra la propiedad privada servían para establecer un pulso con la opinión pública acerca de la necesidad de reforzar la autoridad, resaltar la violencia implícita en la sociedad y apaciguar el recelo de la población señalando el buen funcionamiento de los organismos de seguridad. Cabe resaltar la atención que se muestra a los sucesos relacionados con los accidentes acaecidos en el ámbito privado, un marco difícil de rastrear donde las mujeres y sus hijos e hijas son protagonistas. Es interesante comprobar la disminución de noticias sobre accidentes domésticos durante la Gran Guerra, una coyuntura en la que muchas mujeres se incorporan al mercado laboral movidas por una "economía de neutralidad", que incentivaba la inflación y demandaba mano de obra barata y la producción a destajo en improvisados talleres y otros locales. Este hecho refleja la necesidad de unos pocos empresarios de enriquecerse a toda costa y revela la débil barrera establecida entre lo público y privado.

En el capítulo quinto el autor analiza las páginas de sucesos del diario malacitano La Unión Mercantil, reproduciendo, por tanto, la tipología establecida en el capítulo anterior. Con ello busca establecer similitudes o divergencias entre la prensa de Barcelona y Málaga, proceso en el que detecta el morbo que suscitan en ambos periódicos las noticias de suicidios, robos, asesinatos, accidentes, timos, catástrofes y muertes violentas. En el sexto y último capítulo se produce el cruce de las unidades comparadas, que bosquejan en primer lugar ciertas diferencias en el eje norte-sur y reafirman, pese a ello, un trasfondo similar: la gravedad de la cuestión social no solo en ambas ciudades, sino en toda la geografía peninsular. El análisis de las páginas de sucesos saca a relucir diferentes aspectos. Por una parte, pone de manifiesto la respuesta de diferentes sectores sociales surgidos o desarrollados durante la Restauración; por otra, resalta la actividad propagandística desplegada como mecanismo desmovilizador para evitar las revueltas de las capas populares, hecho que se manifiesta en la inclusión de noticias relacionadas con la acción policial y judicial y la necesidad de trasladar a la opinión pública la idea de estabilidad y buen funcionamiento de un sistema político basado en el orden. En 
último lugar, la investigación muestra, entre otras vicisitudes, los debates ideológicos sobre las luchas sociales y las líneas de tensión entre el progreso y la involución.

En suma, Víctor José Ortega Muñoz pone de relieve la pluralidad de elementos utilizados en el estudio de las noticias de sucesos. Las crisis, desestabilizaciones y revueltas traslucen el devenir de una etapa compleja, envuelta en epidemias, miseria, explotación, violencia, discriminaciones y otros hitos que muestran el potencial de la prensa como fuente histórica, no solo a nivel contextual o cronológico, sino a escala social, política, económica y cultural. Siguiendo a Marc Bloch ${ }^{15}$, la calidad de la fuente periodística, y de otras muchas fuentes, no solo depende de su naturaleza, sino de quiénes la interrogan y cómo lo hacen. Consciente de ello, el autor del libro analiza exhaustivamente las páginas de sucesos de La Vanguardia y La Unión Mercantil y nos invita a reflexionar sobre una temática susceptible de futuras investigaciones, que vaticina interesantes aportaciones sobre la historia social de la prensa y la historia de los resortes de poder en la España contemporánea.

Sergio Blanco Fajardo

15. BLoch, Marc (1963), "Pour une histoire comparée des sociétés européennes" [1928], Mélanges historiques, S.E.V.P.E.N., Paris, p. 20. 